\title{
A legislação educacional para o trabalho no Brasil: do império à primeira república
}

\section{Educational legislation for labor in Brazil: from the empire to the first republic}

\section{Legislación educativa para el trabajo en Brasil: del imperio a la primera república}

\author{
Fernando Silveira Melo Plentz Miranda ${ }^{1}$ \\ Jefferson Carriello do Carmo ${ }^{1}$
}

doi: http://dx.doi.org/10.20435/serie-estudos.v0i0.1450

\begin{abstract}
Resumo: O texto tem por objetivo apresentar as primeiras legislações sobre a educação para o trabalho no Brasil. O foco da análise está na relação entre a história do país e a necessidade de se legislar sobre a educação para o trabalho. Verifica-se que as classes dominantes que governaram o Brasil no passado jamais se preocuparam em desenvolver um projeto de educação inclusiva; pelo contrário, desde o nascimento do Brasil enquanto nação independente, mantiveram uma educação enciclopédica para poucos e a educação para o trabalho destinada aos filhos dos trabalhadores. A partir da leitura dos textos legais e da história brasileira, conclui-se que a gênese da dualidade educacional no Brasil, que se estende até o século XXI, está no processo de independência do país.
\end{abstract}

Palavras-chave: educação para o trabalho; Brasil Império; primeira república.

\begin{abstract}
The text aims to present the first legislation on education for labor in Brazil. The focus of the analysis is on the relationship between the country's history and the need to legislate on education for labor. The ruling classes that ruled Brazil in the past have never bothered to develop an inclusive education project; on the contrary, since the birth of Brazil as an independent nation, they have maintained an encyclopedic education for the few and labor education designed for them to the workers' children. From the reading of the legal texts and the Brazilian history, we concluded that the genesis of the educational duality in Brazil, which extends until the 21st century, is in the process of independence of the country.
\end{abstract}

Keywords: education for labor; Brazil Empire; first republic.

Resumen: El texto tiene como objetivo presentar la primera legislación sobre educación para el trabajo en Brasil. El enfoque del análisis está en la relación entre la historia del país y la necesidad de legislar sobre educación para el trabajo. Se verifica que las clases dominantes que gobernaron Brasil en el pasado nunca se molestaron en desarrollar un proyecto de educación inclusiva; por el

1 Universidade de Sorocaba (Uniso), Sorocaba, São Paulo, Brasil. 
contrario, desde el nacimiento de Brasil como nación independiente, mantuvieron una educación enciclopédica para unos pocos y educación para el trabajo dirigida a hijos de trabajadores. A partir de la lectura de textos legales y de la historia brasileña, se concluye que la génesis de la dualidad educativa en Brasil, que se extiende hasta el siglo XXI, está en proceso de independencia del país.

Palabras clave: educación para el trabajo; Imperio de Brasil; primera república.

\section{Introdução}

No período histórico do início do século XIX, caracterizado pelas profundas transformações decorrentes da Revolução Francesa e da Revolução Industrial que se desenrolaram em fins do século anterior, abriu-se caminho para o avanço do capitalismo no planeta. Na esteira das Guerras Napoleônicas e da hegemonia global inglesa na área econômica, em 1808, a Família Real e a Corte Portuguesa transferiram-se para o Brasil, desencadeando as transformações na Colônia.

Se, por um lado, a presença de portugueses no Brasil não era nenhuma novidade a partir de 1808, por outro lado, doravante, havia a presença das mais altas autoridades portuguesas na Colônia, as quais, evidentemente, estavam acompanhadas por todas as espécies de servidores, dos mais elevados cargos intelectuais aos artífices e trabalhadores especializados portugueses. Diante desse fato, o sistema educacional no Brasil começou a ser normatizado para levar educação intelectual aos filhos dos nobres e educação para o trabalho, para os filhos dos trabalhadores portugueses. Inicia-se, portanto, a dualidade educacional legislada.

O enfraquecimento político e econômico de Portugal propiciou o processo de independência do Brasil, ocorrida em 1822, com a posterior outorga da Constituição Imperial de 1824. Todas as legislações subsequentes em relação à educação para o trabalho, seja no Império, seja na Primeira República, seguem o critério da dualidade educacional que marcou o período e se estende até os dias atuais.

\section{Educação para o trabalho no Brasil Império}

A instalação de indústrias no Brasil Colônia fora proibida pela Coroa Portuguesa, como tentativa de impedir o desenvolvimento econômico da sua principal colônia. Contudo, como consequência da chegada da família real portuguesa e da corte em terras brasileiras em 1808, o príncipe regente Dom João editou um alvará no dia 10 de abril de 1808, permitindo o livre estabelecimento 
de manufaturas e fábricas em território brasileiro. Para incentivar e promover a indústria no Império, nos anos 1820, foi criada a primeira organização brasileira para congregar os interesses dos empresários industriais, a chamada Sociedade Auxiliadora da Indústria Nacional (Sain), que, antes de ser uma associação de classe, objetivava a união de cientistas, políticos e homens de negócios no sentido de explorar os bens naturais e colocá-los a serviço da indústria nascente.

Enquanto alguns países industrializavam-se maciçamente, o Brasil do século XIX mantinha-se economicamente agrário e politicamente conservador, em que pese a independência em 1822. A Constituição brasileira de 1824, monárquica, passou a ser definida como a lei maior e fundamental do país, garantindo os direitos políticos e civis dos cidadãos brasileiros, embora o conceito de cidadania na época fosse extremamente limitado, embasados nos direitos à liberdade e propriedade.

A legislação passou então a ser redigida aos moldes conservadores da classe dominante e escravista da época, como enfatiza Castanha (2013, p. 34):

No Brasil monárquico, apesar de o Imperador dispor do poder Moderador, o governo não se caracterizou como despótico, pois a constituição foi respeitada. As poucas alterações que nela aconteceram, se deram mediante debates e com a aprovação no legislativo. É evidente que a legislação imperial não era avançada para a época, até porque toda legislação traz em si as características da sociedade que a produz. No caso, uma sociedade escravocrata, conservadora, tradicional, com fortes componentes moral e religioso, mas, mesmo assim, as principais conquistas liberais foram asseguradas. A constituição constituiu-se num repositório de leis [...].

Redigida sob influência do iluminismo francês, a Carta Constitucional Imperial mostrou-se contraditória, pois previa as garantias de liberdades individuais aos cidadãos, mas não se opunha à escravidão em terras brasileiras. Outro aspecto controvertido da Carta está previsto no artigo 179, § XXXII, determinando: "A instrucção primária e gratuita a todos os Cidadãos". Em que pese o texto constitucional prever educação a todos os cidadãos, a educação brasileira do século XIX era direcionada quase que exclusivamente para as elites, objetivando a educação propedêutica para os futuros líderes e dirigentes, contribuindo, assim, para a reprodução da sociedade de classes.

Moura (2007) indica que Dom João editou o Decreto de 23 de março de 1809, que cria o Colégio das Fábricas, primeira instituição de ensino destinada 
à formação de mão de obra a ser absorvida pelas indústrias, instituindo a dualidade educacional, uma vez que tal escola era destinada àqueles que deveriam preparar-se para o trabalho fabril.

Essa instituição de ensino foi criada e mantida pelo tesouro real, destinada a educar os artífices e manufatureiros que haviam chegado de Portugal com a família real e que não encontraram trabalho no Brasil, como se percebe pela redação do referido decreto:

DECRETO - de 23 de março de 1809

Dá providencias a bem do serviço da Casa denominada Collegio das Fabricas estabelecido nesta cidade.

Attendendo a acharem-se trabalhando e aprendendo á custa da minha Real Fazenda na Casa denominada Collegio das Fabricas debaixo da direção de Sebastião Fabregas Surigué, meu criado, varios artifices, manufactureiros, aprendizes vindos de Portugal, e isso em virtude das providencias que fui servido dar para a sua subsistencia em utilidade do commercio e industria, que pelo meu Alvará de 10 de Abril do anno proximo passado de 1808 fui servido a promover no Brazil: e tendo consideração ao arranjamento e economia, com que o sobredito Sebastião Fabregas tem promovido o trabalho dos officiaes no dito Collegio, ou Casa do antigo Guindaste, já estabelecidas: hei por bem, que pelo meu Real Erario, na forma até agora praticada, em observancia das minhas Reaes Ordens, se continuem a pagar as folhas dos jornaleiros alli empregados, e as despesas dos reparos da Casa do sobredito Collegio, sendo primeiro assignadas pelo sobredito Director que vencerá $600 \$ 000$ por anno pagos aos quarteis pela folha respectiva debaixo da Inspecção do meu Ministro e Secretario de Estado dos Negocios do Brazil: o qual nomeará para a contabilidade e expedição dos negocios deste estabelecimento os officiaes que julgar necessarios: os quaes serão pagos pelo producto da venda dos gêneros alli fabricados, que será recolhido ao competente cofre debaixo da fiscalisação determinada para todos os objectos de arrecadação, e distribuição da minha Real Fazenda. O Conde de Aguiar, do Conselho de Estado, Presidente do meu Real Erario o tenha assim entendido, e o faça executar com os despachos necessarios, sem embargo de quaisquer leis, regimentos e disposições em contrario. Palacio do Rio de Janeiro, 23 de Março de 1809.

Com a rubrica do Principe Regente Nosso Senhor. (BRASIL, 1809).

Nesse sentido, a primeira escola profissional brasileira era assistencialista, pois mantinha e educava os portugueses pobres no Brasil até que encontrassem trabalhos nas poucas fábricas que estavam instaladas no país. 
A partir de 1840, foram criadas as Casas de Educandos e Artífices e, posteriormente, os Asilos da Infância dos Meninos Desvalidos destinados a menores abandonados, local em que as crianças órfãs eram educadas nas primeiras letras e, após, os egressos eram encaminhados ao trabalho nas oficinas públicas ou privadas.

Desde a sua origem, a educação profissional brasileira está inserida na perspectiva assistencialista, amparando órfãos e desvalidos de toda a sorte. Nasce sob a lógica de uma sociedade preconceituosa ao trabalho manual, que requer o uso das mãos e da força física.

Sobre tal concepção assistencialista da educação profissional, Neves e Pronko (2008, p. 33) afirmam que:

[...] a formação técnico-profissional foi se expandindo desorganizada e assistematicamente, fruto de uma concepção que atribuía a esse tipo de ensino um caráter eminentemente assistencial. Surgido em institutos para incapacitados e menores abandonados, muitos deles de caráter religioso, esse tipo de formação estendeu-se posteriormente aos filhos das camadas populares, seguindo uma concepção que ligava sua difusão à necessidade de "moralização" desses setores da sociedade.

As escolas criadas sob a égide assistencialista para a preparação dos educandos ao trabalho estão associadas ao fato de prepararem mão de obra preponderantemente ao setor privado, notadamente à indústria nascente.

Apesar de a Carta Constitucional Imperial prever no seu artigo 179, § XXIV, que "Nenhum gênero de trabalho, de cultura, industria, ou commercio póde ser prohibido, uma vez que não se oponha aos costumes publicos, à segurança, e saude dos Cidadãos", a indústria brasileira não conseguiu se desenvolver maciçamente por uma série de deficiências. Aponta Prado Júnior (1987) que tais deficiências eram, principalmente, a falta de energia, deficiência de um mercado consumidor, falta de mão de obra especializada, além da ausência de uma siderúrgica em território nacional, elemento essencial ao florescimento de uma base industrial.

Para Manfredi (2002), a elementar indústria brasileira do século XIX permaneceu dependente da economia agrária do período, focada na atividade rural, com objetivo predominante de exportação dos seus produtos primários, importando as manufaturas que se faziam necessárias ao pequeno mercado consumidor interno que se restringia à elite política e econômica brasileira da época. O governo imperial se envolvia na educação para o trabalho apenas quando havia necessidade de 
aporte de grande quantidade mão de obra, quando não estava disponível, como no caso dos arsenais da Marinha e do Exército ou ainda para os hospitais. Essa educação era direcionada aos setores pobres e excluídos da sociedade, tais como os desvalidos, os órfãos e os abandonados. As crianças e os jovens mendicantes eram compulsoriamente encaminhados às casas de educandos e artífices, que adotavam regras militares de disciplina e hierarquia, local em que passavam a receber uma educação para tornarem-se artífices.

Os alunos artífices passavam a trabalhar na indústria que se instalava principalmente na Província de São Paulo, uma vez que a monocultura do café para a exportação dos grãos ao mercado externo propiciou o acúmulo de capital, gerando um ciclo de investimentos que possibilitaria a criação de uma indústria nascente naquela região.

A expansão da economia cafeeira trouxe consigo uma crescente população atraída para as cidades e pelos empregos gerados pela crescente industrialização de alguns centros de serviços. As máquinas instaladas pela indústria brasileira se limitavam à adaptação de equipamentos importados e à adaptação das necessidades locais, com a indústria brasileira se desenvolvendo a partir da importação de máquinas a vapor da Inglaterra. Nessa época, foram construídas as primeiras estradas de ferro ligando o interior do país aos portos, notadamente o porto de Santos, em que eram escoadas as produções de café. À mesma época, foram construídas as primeiras fábricas de fiação e tecelagem.

Esse crescimento industrial foi financiado principalmente pelo excedente de capital cafeeiro, que acabou por possibilitar a expansão da infraestrutura ligada ao plantio do café na Região Sudeste. A indústria passou a demandar mão de obra de acordo com as suas necessidades, surgindo uma dupla necessidade; primeira, a gradual substituição do trabalho escravo pelo trabalho assalariado; segundo, a educação do povo para a condução do desenvolvimento de uma nova ordem econômica e social.

Santos (2000) informa que, com a criação do Liceu de Artes e Ofícios da Província de São Paulo, que tinha como mantenedora a Sociedade Propagadora da Instrução Popular formada por políticos e membros da burocracia estatal, instituiu-se uma escola primária noturna gratuita com o objetivo de ministrar ao povo os conhecimentos necessários ao ofício na lavoura, no comércio ou na indústria. Em outras palavras, estavam a elite política e econômica brasileira 
constituindo e mantendo uma escola destinada às camadas populares da população, para que aprendessem um ofício, formando, portanto, a mão de obra desejada pela indústria.

Alencastro e Renaux (1997) afirmam que, no decorrer do século XIX, travou-se um debate sobre as formas de se manter a produção rural, que estava baseada no escravismo de origem africana, sem os escravos negros. O início da imigração de europeus que vieram trabalhar no Brasil em fins do século XIX, em substituição à mão de obra escrava, ocorreu porque a esmagadora maioria deles eram operários que viviam à beira da miséria em seus respectivos países, podendo se "nivelar" em condições de trabalho dos negros nas fazendas brasileiras.

Além disso, o fato de o Brasil ser um país de dimensões territoriais continentais fez com que o país continuasse dependente de mão de obra externa em face da limitação da oferta de mão de obra interna, estando sujeito às pressões internacionais abolicionistas, uma vez que, para o desenvolvimento do capitalismo liberal, há a necessidade de substituição do trabalho escravo pelo trabalho assalariado.

A abolição da escravatura se insere em um processo de reestruturação econômica da oferta de mão de obra, com o surgimento do assalariamento no Brasil tomando corpo no fim do século XIX, ou seja, a transição do trabalho escravo para o trabalho livre e assalariado ocorreu sob a lógica conservadora, perpetuando o histórico de desigualdades do país.

O término do trabalho escravo e o início do trabalho assalariado no Brasil ocorreram desacompanhados de um processo de alteração social, por falta de interesse da elite política e econômica do país, fazendo com que a educação não se tornasse uma prioridade. Assim, a lógica da educação assistencialista permaneceu, como ressalta Manfredi (2002, p. 78):

Durante o Império, tanto as práticas educativas promovidas pelo Estado como as da iniciativa privada pareciam refletir duas concepções distintas, mas complementares: uma de natureza assistencialista e compensatória, destinada aos pobres e desafortunados, de modo que pudessem, mediante o trabalho, tornar digna a pobreza; a outra dizia respeito à educação como um veículo de formação para o trabalho artesanal, considerado qualificado, socialmente útil e também legitimador da dignidade da pobreza.

Ideológica e politicamente, tais iniciativas constituíam mecanismos de disciplinamento dos setores populares, no sentido de conter ações insurrecionais 
contra a ordem vigente e legitimar a estrutura social excludente herdada do período colonial.

Berger (1984) indica que não havia no Brasil do século XIX as condições necessárias para o surgimento da industrialização autônoma, como ocorrera nos Estados Unidos da América (EUA). O Brasil ocupava uma posição na economia mundial de fornecedor de matérias-primas aos países de economia desenvolvida, estruturado em um sistema de fazendas tradicionais - latifúndio, monocultura e trabalho escravo -, não sendo essas características as mais propícias à ação inovadora que permite o surgimento da industrialização autônoma em larga escala.

A industrialização brasileira desenvolveu-se simplesmente como uma modernização adaptada dos países de economia desenvolvida, na medida em que não houve o desenvolvimento de tecnologia e know-how próprios, mas sim uma assimilação e adaptação de equipamentos e máquinas que foram adquiridas em outros países e instaladas em território nacional.

Com a Proclamação da República em 1889, a lógica aristocrática que já dominava o poder político no Brasil Império se manteve, não havendo na Primeira República (1889-1930) qualquer modificação relevante das relações sociais previamente existentes, basicamente mantendo o país em uma economia agrária fundada no abastecimento do mercado internacional da monocultura do café. 0 ideário liberal europeu do século XIX era adaptado pela elite política brasileira, mostrando-se destituído de uma efetiva democracia participativa e longe das demandas de caráter social.

Contudo, foi na Primeira República que o país iniciou a sua urbanização e industrialização de forma efetiva, passando o trabalho dos operários industriais a ter um papel relevante na sociedade brasileira, momento em que o sistema educacional passou a ganhar nova configuração, notadamente nas cidades.

\section{EDUCAÇÃO PARA O TRABALHO NA PRIMEIRA REPÚBLICA}

A promulgação da Constituição Federal de 1891 (CF/1891), que institucionaliza a República, reorganizou a estrutura política e administrativa do Estado. 0 texto constitucional determina que passa a ser função do Estado desenvolver e ampliar o sistema educacional brasileiro, o que permitiu o surgimento de redes de escolas criadas por iniciativa do poder público federal e estaduais. 
No âmbito da educação profissional, operou-se a ampliação das escolas profissionais, que passaram a absorver os jovens que pertencem às camadas populares da sociedade urbana, transformando-os em potenciais trabalhadores assalariados, constituindo a rede de educação profissional em um "[...] processo institucionalizado de qualificação e disciplinamento dos trabalhadores livres dos setores urbanos" (MANFREDI, 2002, p. 80).

Com o surgimento da República, houve um surto de crescimento industrial chegando a 3.362 indústrias instaladas no Brasil em 1909, ao passo que, em 1889, eram apenas 636 estabelecimentos industriais operantes no país (FONSECA, 1986, p. 173). O desenvolvimento econômico e industrial brasileiro se fez sentir pelo Governo Federal, que criou o Ministério dos Negócios da Agricultura, Indústria e Comércio, por meio do Decreto 1.606/1906. Entre as atribuições desse ministério, estava o desenvolvimento da indústria e dos assuntos destinados à educação profissional, ou seja, os assuntos educacionais passaram a ser definidos pelo ministro da Indústria, que é ligado aos empresários industriais.

O governo do presidente Nilo Peçanha instituiu a primeira legislação específica relativa ao ensino profissional no Brasil, ao emitir o Decreto 7.566/1909, como se percebe pela leitura do texto legal:

DECRETO № 7.566, DE 23 DE SETEMBRO DE 1909

Cria nas capitais dos Estados da República Escolas de Aprendizes Artífices, para o ensino profissional primário e gratuito.

O Presidente da República dos Estados Unidos do Brasil, em execução da lei no 1.606, de 29 de dezembro de 1906 :

Considerando:

que o aumento constante da população das cidades exige que se facilite às classes proletárias os meios de vencer as dificuldades sempre crescentes da luta pela existência;

que para isso se torna necessário, não só habilitar os filhos dos desfavorecidos da fortuna com o indispensável preparo técnico e intelectual, como fazê-los adquirir hábitos de trabalho profícuo, que os afastará da ociosidade, escola do vício e do crime;

que é um dos primeiros deveres do Governo da República formar cidadãos úteis à Nação; [...]. (BRASIL, 1909).

Embora o Decreto 7.566/1909 inaugurasse a regulamentação da educação profissional brasileira, não extinguiu o antigo preconceito desse ramo educacional, 
uma vez que o preâmbulo do decreto deixava evidente que essa educação era destinada aos "desfavorecidos da fortuna", mantendo-se a lógica preconceituosa e discriminatória da educação para o preparo para o trabalho físico ou profissões manuais.

O referido decreto determinava que deveriam ser criadas Escolas de Aprendizes Artífices em cada uma das capitais dos estados, instaladas e mantidas pelo orçamento do Governo Federal e destinadas à formação de mão de obra para as necessidades do setor produtivo, em especial o industrial. Fonseca (1986) informa que, já em 1910, estavam operantes dezenove Escolas de Aprendizes Artífices em território nacional, mas invariavelmente todas abrigadas em edificações inadequadas e com precárias condições de funcionamento das oficinas. Contudo o principal problema era a falta e o despreparo de professores, que na sua maioria eram mestres de letras do ensino primário, não possuindo qualquer preparação para a educação profissional. Em que pesem os problemas iniciais, as Escolas de Aprendizes Artífices constituem-se no gérmen nascedouro das atuais escolas profissionais da rede federal de educação.

A educação profissional que surge com as escolas de Aprendizes Artífices é uma decorrência da economia brasileira, que no início do século XX estava focada exclusivamente na exportação de produtos primários. Abreu (1984) aponta que, nesse período, apenas oito produtos representavam 90\% das exportações: café; açúcar; cacau; algodão; mate; tabaco; borracha; couros e peles. O produto primário essencial das exportações brasileiras era o café, que representava $70 \%$ das remessas de produtos brasileiros ao mercado internacional e que, portanto, era o carro-chefe da economia brasileira, influenciando toda a infraestrutura industrial do país.

A oligarquia cafeeira tornou-se a mais poderosa corrente econômica e política do Brasil, impondo ao país uma sequência de empréstimos internacionais ao longo das duas primeiras décadas do século XX para manter estáveis os preços internacionais do café. Essa política agressiva mantida pela oligarquia cafeeira ocasionou, durante essas décadas, condições favoráveis ao endividamento externo brasileiro, como também um saldo positivo na balança comercial, ocasionando uma explosão de importações de produtos industrializados e bens de consumo de países como a Inglaterra, mas, principalmente, os EUA.

Com a deflagração da Primeira Guerra Mundial, os produtos industrializados importados pelo Brasil deixaram de ser enviados ao país pelas nações beligerantes, 
momento em que o governo brasileiro percebeu a possibilidade de crescimento da indústria nacional. Os cafeicultores, que durante décadas acumularam grandes quantias de capital, passaram a investir na indústria para a produção de bens primários para consumo interno, passando as indústrias nacionais a exercer o monopólio do mercado nacional. Em apenas cinco anos, entre 1915 e 1919, foram criadas 5.936 novas indústrias, com a produção industrial saltando de 1.350 .000 contos de réis em 1914, para 3.000.000 contos de réis em 1920 (FONSECA, 1986, p. 190).

O rápido desenvolvimento da indústria nacional, seguido do aumento da produção industrial brasileira, foi acompanhado da necessidade de formação de mão de obra para a capacitação dos trabalhadores e a adaptação desses às exigências do trabalho industrial. Sensível a esses imperativos da indústria, o governo do presidente Venceslau Brás aprovou um novo regulamento para as Escolas de Aprendizes Artífices, editando o Decreto n. 13.064/1918, que determina o curso primário para todos os alunos, a redução da idade mínima de matrícula de 12 para 10 anos, cursos noturnos para os maiores de 16 anos e a nomeação de diretores por concurso de títulos e de professores por concurso de provas práticas.

Além desses destaques anteriormente apontados, houve uma nítida influência da indústria na redação do regulamento das Escolas de Aprendizes Artífices, como se percebe no art. $2 \stackrel{\circ}{\circ}$, a seguir transcrito:

Art. 2- - Nas escolas de aprendizes artífices procurar-se-há formar operarios e contramestres, ministrando-se o ensino pratico e os conhecimentos technicos necessarios aos menores que pretendem aprender um officio, havendo para isso as oficinas de trabalho manual ou mecanico que forem mais convenientes aos Estados em que funcionarem as escolas, consultadas, quando possivel, as especialidades das industrias locaes. (BRASIL, 1918).

Sob influência da indústria, a regulação da educação profissional brasileira de 1918 vinculava o ensino às necessidades peculiares da indústria do local em que a escola estava instalada, o que demonstra a íntima relação entre o poder político e os empresários industriais.

Para Fonseca (1986), apesar das iniciativas governamentais em legislar e regulamentar a educação profissional, a falta de investimento público na educação se fez sentir nas condições em que se encontravam as Escolas de Aprendizes Artífices, uma vez que invariavelmente as escolas continuavam instaladas em prédios inadequados, com professores na sua maioria sem formação profissional, oficinas mal-aparelhadas e alunos desmotivados. 
Diante das críticas dos industriais e da imprensa ao modelo de educação profissional implantado no país, a partir de 1922 o Governo Federal, por meio do Ministério da Agricultura, Indústria e Comércio, passou a formar comissões para a reformulação desse sistema educacional. A primeira medida prática que o governo adotou para motivar os alunos e aumentar a procura das Escolas de Aprendizes Artífices por parte de novos candidatos foi a introdução da merenda escolar, inserida no mesmo ano de 1922. Tal iniciativa demonstra a manutenção da atitude assistencialista com que o governo tratava a educação profissional brasileira.

Ao longo de cinco anos, foram travados diversos discursos e apresentadas propostas para a reformulação da educação profissional, culminando com a publicação do Decreto n. 5.241/1927. A leitura atenta do artigo 4o deste decreto revela uma astúcia do governo:

DECRETO № 5.241, de 22 de agosto de 1927

$[\ldots]$

Art. 4-- O certificado de habilitação profissional assegurará, em igualdade de condições, o direito de nomeação ao que o possuir entre os candidatos a funções públicas quaisquer da União. [...]. (BRASIL, 1927).

Assim, abriu-se a possibilidade de incentivar as matrículas nas escolas de educação profissional que já existiam e que se pretendiam constituir pela via de privilégios para a contratação com o Governo Federal. Pelo referido artigo legal, quando dois ou mais candidatos a um cargo público concorressem em iguais condições, aquele que possuísse um certificado emitido por uma escola profissional seria o escolhido. Ocorre que tais critérios de contratação com a União jamais se implementaram, mantendo a educação profissional destinada a suprir mão de obra para a indústria brasileira.

Durante todo o processo de instalação e operação das Escolas de Aprendizes Artífices e outros estabelecimentos de educação profissional constituídos no país, houve a gradativa industrialização das escolas com a aceitação dos diretores de encomendas para a produção de bens para entidades privadas ou órgãos públicos, que forneciam matérias-primas e pagavam à escola a mão de obra e os demais serviços. Dessa forma, as escolas permaneciam à disposição da indústria privada, que assim acabava por estabelecer contratos de produção com as escolas, operando a subcontratação de trabalhadores que eram estudantes. 
Percebe-se que, durante a Primeira República, os governos que se sucederam elaboraram uma sequência de decretos que visavam legislar sobre a educação profissional, no sentido de suprir as necessidades de formação de mão de obra para a indústria brasileira. Tornou-se uma tentativa frustrada de ampliar o acesso da população à educação profissional, sendo que tais alterações legislativas realizadas durante o período não obtiveram êxito, uma vez que nenhum grupo social de origem popular estava organizado e em condições de expressar as suas reais necessidades e desejos educacionais, estando a educação profissional a serviço da indústria. Assim, o "[...] sistema educacional continuava a orientar-se pela herança da escola jesuítica, o que na prática significava que a escola brasileira era de conteúdo intelectualista, alienada da realidade e sem vinculação ao mundo do trabalho, servindo por isso exclusivamente à classe dominante" (BERGER, 1984, p. 170).

\section{Considerações finais}

Buscamos, neste estudo, identificar as primeiras legislações brasileiras no que concerne à regulamentação da educação para o trabalho. Buscando compreendê-las, ao realizarmos a análise dos textos legais à luz dos fatos históricos do Brasil Império e da Primeira República, percebemos que os governantes do período vincularam a educação profissional no Brasil, desde sua gênese, à formação de mão de obra a ser utilizada para fins específicos do mercado de trabalho. Em outras palavras, a preocupação dos governantes, que se reflete na legislação, estava vinculada à formação de mão de obra que atendesse às necessidades do mercado.

Percebemos que a educação para o trabalho no Império, ainda sob a égide da degradante escravidão, estava destinada inicialmente aos filhos órfãos do país, sendo de cunho assistencialista e preconceituosa. Com o fim da escravidão e do Império, o Brasil renovado politicamente na Primeira República iniciou a sua inserção na lógica do sistema econômico capitalista, vinculando a educação profissional às necessidades da indústria e do mercado de trabalho, mantendo, dessa forma, os preconceitos da sociedade contra a educação profissional e cristalizando a dualidade educacional que se mantém até os dias atuais. 


\section{REFERÊNCIAS}

ABREU, Marcelo de Paiva. O Brasil e a economia mundial (1929-1945). p. 9-49. In: FAUSTO, Boris (Org). O Brasil republicano. Economia e cultura. São Paulo: Difel, 1984. Tomo III, v. 4.

ALENCASTRO, Luiz Felipe; RENAUX, Maria Luiza. Caras e modos dos migrantes e imigrantes5. In: NOVAIS, Fernando Antonio; ALENCASTRO, Luiz Felipe (Org.). História da vida privada no Brasil. Império: a corte e a modernidade nacional. São Paulo: Companhia das Letras, 1997. p. 291-33. v. 2

BERGER, Manfredo. Educação e dependência. 4. ed. São Paulo: Difel, 1984.

BRASIL. Decreto n. 5.241, de 22 de agosto de 1927. Crêa o ensino profissional obrigatorio nas escolas primarias subvencionadas ou mantidas pela União, bem como no Collegio Pedro II e estabelecimentos a este equiparados e dá outras providencias. Rio de Janeiro, 1927.

BRASIL. Decreto n. 13.064, de 12 de junho de 1918. Dá novo regulamento ás Escolas de Aprendizes Artifices. Rio de Janeiro, 1918.

BRASIL. Decreto n. 7.566, de 23 de setembro de 1909. Cria nas capitais dos Estados da República Escolas de Aprendizes Artífices, para o ensino profissional primário e gratuito. Rio de Janeiro, 1909.

BRASIL. Decreto n. 1.606, de 29 de dezembro de 1906. Crêa uma Secretaria de Estado com a denominação de Ministerio dos Negocios da Agricultura, Industria e Commercio. Rio de Janeiro, 1909.

BRASIL. Constituição da República dos Estados Unidos do Brasil. Promulgada em 24 de fevereiro de 1891. Rio de Janeiro, 1891.

BRASIL. Constituição de 1824. Constituição Política do Império do Brasil, elaborada por um Conselho de Estado e outorgada pelo Imperador D. Pedro I, em 25 de março de 1824. Rio de Janeiro, 1824.

BRASIL. Decreto de 23 de março de 1809. Dá providencias a bem do serviço da Casa denominada Collegio das Fabricas estabelecido nesta cidade. Rio de Janeiro, 1824.

CASTANHA, André Paulo. Edição crítica da legislação educacional primária do Brasil imperial: a legislação geral e complementar referente à Corte entre 1827 e 1889. Campinas: Navegando, 2013. 
FONSECA, Celso Suckow. História do ensino industrial no Brasil. Rio de Janeiro: Senai/ DN/DPEA, 1986. v. 1.

MANFREDI, Silvia Maria. Educação profissional no Brasil. São Paulo: Cortez, 2002.

MOURA, Dante Henrique. Educação básica e educação profissional e tecnológica: dualidade histórica e perspectivas de integração. Holos, Natal, ano 23, v. 2, p. 4-30, 2007.

NEVES, Lúcia Maria Wanderley; PRONKO, Marcela Alejandra. O mercado do conhecimento e o conhecimento para o mercado: da formação para o trabalho complexo no Brasil contemporâneo. Rio de Janeiro: EPSJV, 2008.

PRADO JÚNIOR, Caio. A Revolução Brasileira. 7. ed. São Paulo: Brasiliense, 1987.

SANTOS, Jailson Alves. A trajetória da educação profissional: da Colônia à Primeira República. In: LOPES, Eliane Marta Santos Teixeira; FARIA FILHO, Luciano Mendes de; VEIGA, Cynthia Greive (Org.). 500 anos de educação no Brasil. 2. ed. Belo Horizonte: Autêntica, 2000. p. 205-24.

\section{Sobre os autores:}

Fernando Silveira Melo Plentz Miranda: Doutor em Educação. Mestre em Direito. Coordenador e professor do curso de Direito da Universidade de Sorocaba (Uniso). Pesquisador do Grupo de Estudos Instituição Escolar: História, Trabalho e Políticas de Educação Profissional. Orcid: https://orcid.org/0000-0001-5110-4545. E-mail: fernando.plentz@prof.uniso.br; fsmpmiranda@gmail.com

Jefferson Carriello do Carmo: Pós-doutor em História Social do Trabalho pela Universidade Estadual de Campinas (Unicamp). Doutor e mestre em Educação pela Unicamp. Professor pesquisador do Programa de Pós-Graduação em Educação da Universidade de Sorocaba (Uniso). Líder e pesquisador do Grupo de Estudos Instituição Escolar: História, Trabalho e Políticas de Educação Profissional - CNPq. Orcid: https://orcid.org/0000-0002-6816-5667. E-mail: jefferson.carmo@prof.uniso.br; jeffccprof@gmail.com

\section{Recebido em: 20 de maio de 2020}

Aprovado em: 1 de outubro de 2020 
